\title{
METAL FRACTIONATION IN SEDIMENTS: A COMPARATIVE ASSESSMENT OF FOUR SEQUENTIAL EXTRACTION SCHEMES
}

\author{
Zakir, H. M. ${ }^{1,2}$ and Naotatsu SHIKAZONO 3 \\ ${ }^{1} \mathrm{Ph}$. D. Student, Laboratory of Geochemistry, Dept. of Applied Chemistry, Keio University \\ (3-14-1, Hiyoshi, Kohoku-ku, Yokohama 223-8522, Japan) \\ E-mail: zakirhm.ac.bau@gmail.com \\ 2 Assistant Professor, Dept. of Agricultural Chemistry, Bangladesh Agricultural University \\ (Mymensingh 2202, Bangladesh) \\ 3 Professor, Laboratory of Geochemistry, Dept. of Applied Chemistry, Keio University \\ (3-14-1, Hiyoshi, Kohoku-ku, Yokohama 223-8522, Japan) \\ E-mail: sikazono@applc.keio.ac.jp
}

Four sequential chemical extraction schemes for metal analysis (a 4-step modified protocol originally proposed by the Standards, Measurements and Testing Programme (SM\&T - formerly BCR) of the European Union, Tessier and Hall 5-step procedures and 6-step Grimalt's scheme) were compared. Each procedure was applied to four sediment samples collected from two rivers, Nakagawa (NR) and Tamagawa (TR), Tokyo, Japan. Additionally, a certified marine sediment reference material (JMS-1) was also extracted for the comparison. To evaluate the partitioning of metals among different geochemical forms, the concentration of chromium $(\mathrm{Cr})$, copper $(\mathrm{Cu})$, nickel $(\mathrm{Ni})$, lead $(\mathrm{Pb})$ and zinc $(\mathrm{Zn})$ were measured by Zeeman-corrected atomic absorption spectrometry. Other major elements and mineralogy of sediments were also determined on bulk prior to extracting by X-ray fluorescence (XRF) and X-ray diffraction (XRD) analysis, respectively, which allowed qualitative correlation between the fractionation results obtained and the presence of defined geochemical phases. The total concentrations of metals were determined after strong acid attack and the analytical precision was verified by using JMS-1. Significant proportions of elements were found in non-residual fractions among the schemes (average 83, 91, 76, 93 and 59\% for $\mathrm{Cr}$, $\mathrm{Cu}, \mathrm{Pb}, \mathrm{Zn}$ and $\mathrm{Ni}$, respectively) in the more anthropogenically impacted NR sediments. The highest mobility was observed for $\mathrm{Pb}$ and $\mathrm{Zn}$ among the four schemes while the lowest was for $\mathrm{Cr}$ and $\mathrm{Ni}$. Results of the comparison among the total metal levels for the four schemes based upon the sum of sequential extraction steps for each element showed significant differences for $\mathrm{Cr}$, Ni and $\mathrm{Zn}$. On the other hand, the sum of non-residual phases of the four schemes showed no significant differences for $\mathrm{Cr}, \mathrm{Cu}$ and $\mathrm{Zn}$ but the $\mathrm{SM} \& \mathrm{~T}$ and Hall schemes showed significant differences from others for $\mathrm{Pb}$ and $\mathrm{Ni}$, respectively. Generally, good recoveries were achieved with the Hall scheme (range 92-109\%) and the Fe-Mn oxides occlued phase of this scheme was the most effective owing to the high tendency to extract metals. In addition, Grimalt scheme produced the lowest recovery of $\mathrm{Cr}$ and the concentrations of residual fraction of other elements were also lower.

Key Words : Sequential extraction,Fractionation, Metal distribution, Sediment

\section{INTRODUCTION}

Metals like $\mathrm{Cr}, \mathrm{Cu}, \mathrm{Ni}, \mathrm{Pb}, \mathrm{Zn}$ and others are most important among the frequently observed contaminants in soil and sediments. Both industrial activities and urbanization have greatly increased the metal burden in the environment. Deposition of metal-rich wastes through different anthropogenic activities (such as mine tailings, metal smelting, leather tanning, electroplating, emissions from gas exhausts, energy and fuel production, intensive agriculture and sludge dumping and others) 
contaminate environmental systems with nonbiodegradable toxic metals ${ }^{1)}$. The list of sites contaminated with metals grows every year, presenting a serious problem for human health and a formidable danger to the environment ${ }^{2)}$. The west bank of NR at Kazeno Hiroba (Higashi-Ohjima of Edogawa Ward, Tokyo, Japan) is one such location where a significant amount of industrial metal contained waste was deposited, particularly Cr. Data obtained by speciation and knowledge concerning to the distribution of metals in soils and sediments can be used as useful tools to extrapolate the degree to which metals and their compounds are mobile, extractable and plant-available ${ }^{3,4,5)}$. Sequential extraction schemes are recognized to be a necessary tool to obtain such information as total concentration does not provide suitable information about the bioavailability of potentially toxic elements. Four to eight extractants are usually employed in an order in which the earlier ones are the least aggressive and the most specific, and subsequent extractants are progressively more destructive and less specific. Regardless of the schemes used there have been a number of problems identified such as reagents that are insufficiently specific to dissolve target phases and there is potential for substantial redistribution of metals among the phases during extracting processes. Thus, there is no reagent with a single phase specific to the removal of metals ${ }^{6}$. It is generally assumed that the availability of the metals to the living organisms follows a decreasing order from the first step towards the last step in a sequential extraction scheme. The extent of overlap occurring between the various fractions is a subject of discussion. However, it is probable that up to the oxide occluded forms in different schemes of sequential extractions represent the forms of the metals that are more available than the metals in the last fractions. Therefore, the changes in the proportion of metals bound in these fractions can be used as an indication of possible important environmental changes ${ }^{7,8)}$.

There are a wide variety of sequential extraction procedures available in literature based on a different sequence of extractants and/or different operating conditions 9, 10,11,12,13). Among those, the 4-step SM\&T (formerly BCR scheme, modified by Rauret et al. ${ }^{14)}$ ) and the 5-step Tessier ${ }^{15)}$ schemes are most widely accepted. A similar method to the Tessier scheme is described by Grimalt ${ }^{16)}$ and includes a water soluble phase (deionized $\mathrm{H}_{2} \mathrm{O}$ ). In the Hall scheme $^{17)}$, the oxide/ reducible phase is divided into metals associated with amorphous Fe oxyhydroxide and crystalline oxides of Fe. Both the SM\&T and Hall schemes combine the exchangeable and carbonate phases into one fraction.

The aim of this study was to compare the results from four sequential extraction procedures used for partitioning metals in two different types of sediments. In comparison, emphasis was given to the non-residual phases of metal as these are widely used to determine the anthropogenic pollution levels in solid materials. The methods were chosen because of their similarities and capacity to generate specific information on the type of materials considered. The study was focused on the five elements of toxicological interest $(\mathrm{Cr}, \mathrm{Cu}, \mathrm{Pb}, \mathrm{Ni}$ and $\mathrm{Zn})$, that may be associated with anthropogenic activities. The methods have been applied to four sediment samples collected from the two rivers (NR and TR) near Tokyo, Japan and JMS-1, a certified marine sediment ${ }^{18)}$ for which no information regarding phase dependent composition is available although the $\mathrm{Cr}$ content of JMS-1 has been analyzed recently ${ }^{19)}$ by using X-ray near edge structure.

\section{EXPERIMENTAL MATERIALS AND METHODS}

\section{(1) Reagents and instrumentation}

All chemicals and reagents were of analytical reagent grade quality (Sigma-Aldrich, USA and Wako, Japan). Millipore water was used throughout all the experiments. Before use, all glass and plastic ware were soaked in $14 \% \mathrm{HNO}_{3}$ for $24 \mathrm{hrs}$. The washing was completed with Millipore water rinse.

Atomic absorption measurements were performed with a Hitachi Z-6100 Polarized Zeeman spectrophotometer, equipped with single element hollow-cathode lamps. The instrument was operated at maximum sensitivity with an air-acetylene flame. Lamp current and slit width were used according to the manufacturer's recommendation. The instrumental parameters used for each element are shown in Table 1. A centrifuge (Kokusan H-27F, Tokyo, Japan) for complete separation of the extract from the residue, a Yamato SA-320 (Tokyo, Japan) shaker and a Toa-Dkk HM-20P (Tokyo, Japan) pH meter were used throughout all the experiments.

A preliminary quantitative determination of major elements of the samples was carried out by X-ray Fluorescence spectroscopy, employing a Rigaku RIX 1000 (Tokyo, Japan) XRF. For the preparation of beads, $0.4000 \pm 0.0005 \mathrm{~g}$ dry oxidized (at $900^{\circ} \mathrm{C}$ for $14 \mathrm{hrs})$ samples, lithium tetraborate $(4.0 \mathrm{~g})$ and lithium iodide $(50 \mathrm{mg})$ were mixed 
Table 1 Instrumental and experimental parameters for the metals

\begin{tabular}{|l|c|c|c|c|c|}
\hline \multirow{2}{*}{ Parameters } & \multicolumn{5}{|c|}{ Metals } \\
\cline { 2 - 6 } & $\mathrm{Cr}$ & $\mathrm{Cu}$ & $\mathrm{Ni}$ & $\mathrm{Pb}$ & $\mathrm{Zn}$ \\
\hline Electric current $(\mathrm{mA})$ & 7.5 & 7.5 & 10.0 & 7.5 & 5.0 \\
Wavelength $(\mathrm{nm})$ & 359.3 & 324.8 & 232.0 & 283.3 & 213.9 \\
Slit width $(\mathrm{nm})$ & 1.3 & 1.3 & 0.2 & 1.3 & 1.3 \\
Analytical working range $\left(\mu \mathrm{g} \mathrm{ml}^{-1}\right)$ & $0.5-4.0$ & $0.5-8.0$ & $0.5-4.0$ & $1.0-8.0$ & $0.1-1.0$ \\
Determination limit $\left(\mu \mathrm{g} \mathrm{m}^{-1}\right)$ & 100 & 30 & 20 & 200 & 4 \\
\hline
\end{tabular}

together and used a Bead Sampler NT-2100 (Tokyo, Japan). The X-ray tube features a $20-60 \mathrm{kV} / 80 \mathrm{~mA}$ power supply, chromium transmission target and a beryllium side window. Analyzing crystals are in four positions consist with lithium fluoride ( $\mathrm{LiF}$ [200]), penta-erythritol (PET [002]) and germanium (Ge [111]). Gas flow proportional counter (PC) and source slit diameter are same $(0.45 \mathrm{~mm})$ while the scintillation counter (SC) diameter is $0.15 \mathrm{~mm}$. Scintillation counter consist of a scintillating crystal of NaI doped with thallium attached to a photomultiplier (R580 HTV). Plate calibration was performed using geological standards (JB-3, JF-1, JG-2, JGb-2, JH-1 and JSy-1) following the manufacturer's recommendations. The results are calculated considering the ignition loss and expressed in mass percent. A Bruker AXS: D-8 Advance (Berlin, Germany) X-ray diffractometer was employed for XRD analysis.

\section{(2) Collection and preparation of samples}

Bed sediment samples were collected from Nakagawa River (located in the eastern part of Tokyo, Japan) and Tamagawa River (located in the western part of Tokyo, Japan). Between them, NR is shorter in length, depth and width than TR and receives significant amount of industrial discharges, municipal wastewater and others. And NR possesses almost muddy sediments without coarse sand while TR has typical sediments with coarse sand. The samples from NR were collected at Kazeno Hiroba (Higashi-Ohjima of Edogawa Ward, Tokyo) and from TR at the Taishi Bridge (Taishigawara, Kawasaki). Kazeno Hiroba residents indicated industrial wastes containing metals including $\mathrm{Cr}$ were deposited about 30 years ago. Two samples were collected from each river, and sampling sites were separated by a distance of about $300 \mathrm{~m}$. The sample mass collected in each case was about $500 \mathrm{~g}$. Sub-samples of the material were oven dried at $50^{\circ} \mathrm{C}$ for $24 \mathrm{hrs}$ and sieved (aperture $125 \mu \mathrm{m}$ ). The lower particle size fraction was homogenized by grinding in an agate mortar and stored in glass bottles until the sequential extraction analyses were carried out.

\section{(3) Procedures}

The sequential extraction procedures applied are shown in Table 2. All the operations were carried out in $50 \mathrm{~mL}$ polypropylene centrifuge tubes (Nalgene, New York) and Teflon (PTFE) containers provided with screw stoppers. The initial sediment mass was $1.0000 \pm 0.0005 \mathrm{~g}$. The extracts were separated from the solid residue by centrifugation at $4000 \mathrm{rpm}$ for 30 $\mathrm{min}$. The residue was washed with $10 \mathrm{~mL}$ millipore water in between the successive steps and the supernatant washings added to the same container. The final solution volume was $50 \mathrm{~mL}$. An additional filtration step through Millipore $0.45 \mu \mathrm{m}$ filter was introduced, in order to prevent the errors due to suspended materials and to avoid the AAS nebulizer blocking with micro particles potentially remaining in the suspension. Analytical determinations were carried out on four independent replicates for all samples. Blanks were run simultaneously at all stages of the procedure. Only blank values below the instrumental limits of detection were considered acceptable.

For total metal determinations, $1.0000 \pm 0.0005 \mathrm{~g}$ of dried sediment was digested as described by Tessier et al. ${ }^{15)}$ in a PTFE container. The recovery values (\%) were investigated using the results of total metal analyses. Sequential and total extractions were also performed on JMS-1 provided by the Geological Survey of Japan. All strong acid mixtures were prepared just before the analysis of total metal contents.

\section{(4) Statistical analyses}

Statistical analyses were performed to compare the results as described by Douglas ${ }^{20)}$. Comparisons were made by using one way analysis of variance 
Table 2 Comparative summary of the four sequential extraction procedures

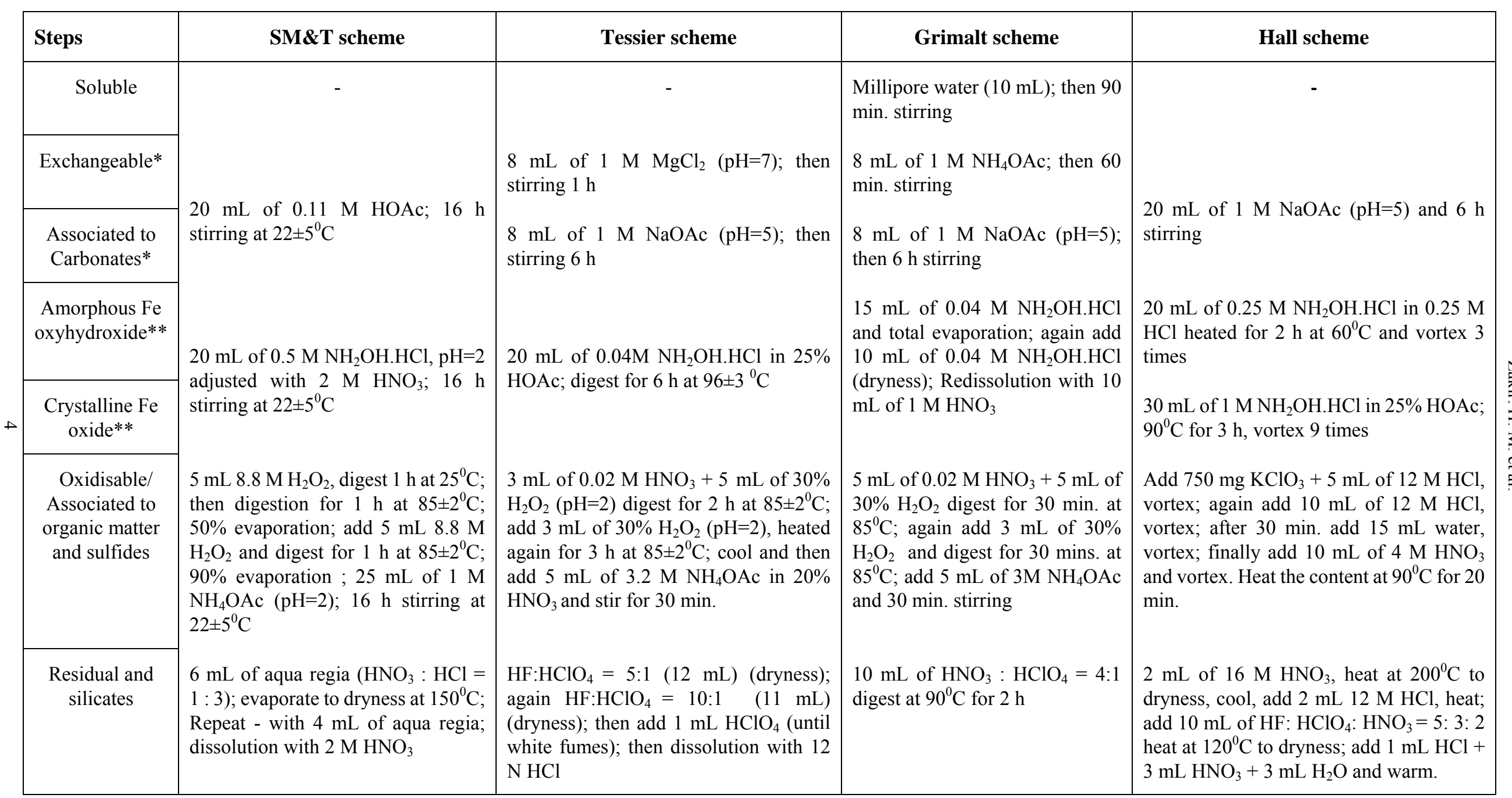

* combined in SM\&T and Hall schemes as Exchangeable + Carbonatic and AEC (adsorbed, exchangeable and carbonate), respectively

** combined in three schemes as Reducible (SM\&T)/ Bound to Fe-Mn oxides (Tessier)/ Associated to oxides (Grimalt) 
(ANOVA) with log transformed data, which was followed by post hoc (Tukey's) tests, as appropriate. Measurements are given as mean \pm standard error, unless noted.

\section{RESULTS AND DISCUSSION}

\section{(1) Major elemental composition of the samples}

Major oxide components of sediment samples are listed in Table 3. It is apparent from Table 3 that NR sediment samples contained higher amounts of iron (approx. 4 times), magnesium (almost double), calcium (about twice) and phosphorus (about 12 times) than TR sediment. Major component concentrations suggest, besides the obvious presence of quartz, other aluminosilicate minerals, as well as the presence of iron oxides, and to a lesser extent, manganese, titanium and phosphorus containing mineral phases. Analytical recoveries for the major elements from JMS-1 ranged 94-108 \% except phosphorus $(83 \%)$.

Additional independent information on the component geochemical phases of all the samples studied was obtained by XRD analysis. Due to the lack of sensitivity of the technique in the case of trace/ minor components, only major crystalline phases could be identified. Quartz, feldspars (such as albite/ anorthite) and calcite were common in both river sediment samples. It is worth mentioning that the chlorite was detected only in NR sediments. Minerals of the mica group (muscovite, biotite) together with quartz and feldspar were detected in NR sediments and JMS-1 standard material. Additionally, the presence of iron hydroxide group minerals, specifically goethite, were detected in NR and JMS-1 reference material and iron phosphate group mineral in NR sediment. The mineral composition of all the samples agrees qualitatively with the major elemental composition determined by XRF.

\section{(2) Comparison on the basis of total metal contents and elemental recoveries}

A comparison between total concentrations obtained by strong acid attack and the sum of the individual concentrations in the fractions of sequential extraction scheme was done for all the schemes and samples used and the results are presented in Table 4, where, each value is the mean of four independent determinations, and the standard deviation $( \pm \mathrm{SD})$ is also added. This comparison offers an alternative path to check for possible systematic errors arising from element losses, contamination or other undetermined causes during the numerous manipulations carried out in the course of sequential extractions. Validation of the method was performed by similar analysis of JMS- 1 . The determined and certified reference concentration values have been included in Table 4 and found to be in acceptable agreement. However, a rigorous validation of the complete sequential methods through assessment of accuracy was not possible because standard reference materials certified regarding the phase dependent composition were not available to us although there are reports of some such certified materials found in literature ${ }^{21,22,23)}$.

A comparison was also done between the total metals contents obtained by single extraction and the

Table 3 Major constituents and their concentrations (mass \%) obtained by XRF in different sediment samples and geological standard

(JMS-1)

\begin{tabular}{|c|c|c|c|c|c|c|c|c|c|c|c|}
\hline \multirow{2}{*}{\multicolumn{2}{|c|}{ Samples }} & \multicolumn{10}{|c|}{ Major constituents } \\
\hline & & $\mathrm{SiO}_{2}$ & $\mathrm{TiO}_{2}$ & $\mathbf{A l}_{2} \mathbf{O}_{3}$ & $\mathrm{Fe}_{2} \mathrm{O}_{3}$ & MnO & MgO & $\mathrm{CaO}$ & $\mathrm{Na}_{2} \mathrm{O}$ & $\mathbf{K}_{2} \mathbf{O}$ & $\mathbf{P}_{2} \mathbf{O}_{5}$ \\
\hline \multicolumn{2}{|l|}{ NR - 1} & 58.62 & 0.81 & 13.33 & 15.47 & 0.13 & 3.30 & 2.87 & 2.55 & 1.90 & 1.03 \\
\hline \multicolumn{2}{|l|}{ NR - 2} & 57.84 & 0.71 & 13.20 & 16.81 & 0.12 & 3.17 & 2.43 & 2.44 & 1.80 & 1.39 \\
\hline \multicolumn{2}{|l|}{ TR - 1} & 76.94 & 0.45 & 11.11 & 4.25 & 0.11 & 1.75 & 1.26 & 1.99 & 2.09 & 0.06 \\
\hline \multicolumn{2}{|l|}{ TR - 2} & 73.71 & 0.59 & 12.54 & 5.28 & 0.10 & 1.63 & 1.41 & 2.24 & 2.36 & 0.15 \\
\hline \multirow{2}{*}{ JMS-1 } & Measured* & 60.73 & 0.83 & 17.65 & 8.19 & 0.13 & 3.04 & 2.35 & 4.31 & 2.60 & 0.17 \\
\hline & Certified** & 60.71 & 0.79 & 17.87 & 7.52 & 0.12 & 3.24 & 2.41 & 4.60 & 2.53 & 0.20 \\
\hline
\end{tabular}

* Ignited matter basis; ** Dry matter basis 
Table 4 Comparison between total metal concentrations (in $\mu \mathrm{g} \mathrm{g}^{-1} \pm \mathrm{SD}^{\mathrm{a}}$ ) and the sum of fractions of different schemes

\begin{tabular}{|c|c|c|c|c|c|c|}
\hline \multirow{2}{*}{ Sample } & \multirow{2}{*}{ Schemes } & \multicolumn{5}{|c|}{ Heavy Metals } \\
\hline & & $\mathrm{Cr}$ & $\mathrm{Cu}$ & $\mathbf{N i}$ & $\mathbf{P b}$ & $\mathbf{Z n}$ \\
\hline \multirow{5}{*}{ NR-1 } & Total & $916 \pm 7.9$ & $362 \pm 2.0$ & $126 \pm 0.9$ & $229 \pm 1.8$ & $1197 \pm 1.23$ \\
\hline & SM\&T & $884 \pm 11.2$ & $339 \pm 6.2$ & $122 \pm 2.6$ & $227 \pm 1.2$ & $1147 \pm 4.1$ \\
\hline & Tessier & $914 \pm 2.6$ & $379 \pm 6.7$ & $104 \pm 1.3$ & $239 \pm 2.6$ & $1169 \pm 14.3$ \\
\hline & Grimalt & $672 \pm 7.1$ & $307 \pm 3.4$ & $104 \pm 2.5$ & $188 \pm 1.7$ & $1057 \pm 8.2$ \\
\hline & Hall & $911 \pm 3.6$ & $390 \pm 2.0$ & $118 \pm 1.5$ & $235 \pm 1.1$ & $1165 \pm 6.5$ \\
\hline \multirow{5}{*}{ NR-2 } & Total & $822 \pm 4.7$ & $344 \pm 2.1$ & $113 \pm 1.7$ & $204 \pm 2.2$ & $1157 \pm 5.3$ \\
\hline & SM\&T & $807 \pm 9.4$ & $325 \pm 4.9$ & $109 \pm 2.0$ & $209 \pm 2.1$ & $1103 \pm 6.4$ \\
\hline & Tessier & $832 \pm 5.2$ & $359 \pm 4.6$ & $96.3 \pm 2.7$ & $204 \pm 3.3$ & $1163 \pm 9.7$ \\
\hline & Grimalt & $630 \pm 9.9$ & $306 \pm 5.0$ & $95.5 \pm 0.9$ & $195 \pm 3.1$ & $1125 \pm 7.0$ \\
\hline & Hall & $828 \pm 6.1$ & $379 \pm 3.4$ & $103 \pm 0.8$ & $230 \pm 2.3$ & $1160 \pm 5.4$ \\
\hline \multirow{5}{*}{ TR-1 } & Total & $266 \pm 2.8$ & $27.3 \pm 0.2$ & $85.5 \pm 2.2$ & $34.7 \pm 0.5$ & $136 \pm 2.2$ \\
\hline & SM\&T & $233 \pm 6.7$ & $28.8 \pm 1.7$ & $85.5 \pm 0.4$ & $34.2 \pm 1.3$ & $133 \pm 3.9$ \\
\hline & Tessier & $241 \pm 6.4$ & $26.5 \pm 1.0$ & $81.6 \pm 2.8$ & $34.2 \pm 0.6$ & $133 \pm 4.7$ \\
\hline & Grimalt & $139 \pm 5.8$ & $27.3 \pm 0.8$ & $72.0 \pm 1.5$ & $28.1 \pm 1.4$ & $115 \pm 4.7$ \\
\hline & Hall & $245 \pm 4.1$ & $28.9 \pm 0.9$ & $80.3 \pm 1.7$ & $35.9 \pm 0.4$ & $141 \pm 3.1$ \\
\hline \multirow{5}{*}{ TR-2 } & Total & $296 \pm 3.2$ & $33.1 \pm 1.2$ & $61.0 \pm 1.4$ & $28.6 \pm 1.0$ & $159 \pm 3.0$ \\
\hline & SM\&T & $256 \pm 5.9$ & $30.5 \pm 2.1$ & $60.9 \pm 0.5$ & $27.6 \pm 1.4$ & $159 \pm 2.1$ \\
\hline & Tessier & $274 \pm 7.5$ & $33.3 \pm 2.2$ & $58.2 \pm 1.9$ & $29.5 \pm 3.2$ & $157 \pm 6.1$ \\
\hline & Grimalt & $165 \pm 7.5$ & $28.6 \pm 0.6$ & $53.5 \pm 2.5$ & $21.7 \pm 1.5$ & $129 \pm 3.6$ \\
\hline & Hall & $273 \pm 5.2$ & $36.3 \pm 1.3$ & $54.7 \pm 1.6$ & $31.1 \pm 1.2$ & $159 \pm 2.0$ \\
\hline \multirow{6}{*}{ JMS-1 } & Total & $138 \pm 2.9$ & $84.9 \pm 2.0$ & $57.9 \pm 1.3$ & $49.2 \pm 1.5$ & $274 \pm 2.2$ \\
\hline & SM\&T & $115 \pm 1.6$ & $89.9 \pm 2.4$ & $61.5 \pm 1.2$ & $49.4 \pm 0.9$ & $270 \pm 2.6$ \\
\hline & Tessier & $140 \pm 1.5$ & $81.2 \pm 0.4$ & $57.7 \pm 0.8$ & $49.3 \pm 2.1$ & $272 \pm 3.3$ \\
\hline & Grimalt & $89.1 \pm 1.9$ & $75.6 \pm 1.3$ & $59.3 \pm 1.4$ & $42.4 \pm 1.8$ & $260 \pm 4.1$ \\
\hline & Hall & $142 \pm 1.1$ & $91.8 \pm 1.9$ & $58.1 \pm 0.8$ & $48.8 \pm 0.8$ & $263 \pm 3.0$ \\
\hline & $\begin{array}{l}\text { Certified } \\
\text { values }\end{array}$ & $133 \pm 2$ & $88 \pm 2$ & $53 \pm 2$ & $49 \pm 2$ & $264 \pm 3$ \\
\hline
\end{tabular}

${ }^{\text {a }}$ Number of replicates: 4, SD: Standard deviation

levels for the four schemes based upon the sum of sequential extraction steps for each element by using Student's $t$-test ${ }^{20)}$. When it was done, there was no significant difference observed for $\mathrm{Cu}$ and $\mathrm{Pb}$ at $95 \%$ confidence level for all river sediment samples and JMS-1. But there were significant differences for $\mathrm{Cr}$, $\mathrm{Ni}$ and Zn for NR-1, NR-2, TR-1, TR-2 and JMS-1 at $\alpha=0.05$. It is evident from Table 4 that the $\mathrm{Cr}$ and $\mathrm{Zn}$ contents especially the $\mathrm{Cr}$ content obtained from the Grimalt scheme were very much lower than those of the others schemes used. On the other hand, the Ni content for the SM\&T scheme was higher than that of the others schemes at $99 \%$ confidence level. But their standard deviation values, which were lower than those of the others, indicate that the sequential extraction schemes produce good 
reproducible results.

Validation of the analytical results was also tested by recovery calculations. An important consideration in the reliability of sequential extraction data is the percent recovery relative to a total digestion. The apparent recovery was calculated following the method as described by Sutherland et al. ${ }^{24)}$ :

\section{$\Sigma_{\mathrm{n}}$ Sequential extraction procedure $\times 100$}

Recovery $_{\mathrm{n}}=$

$$
\text { Total digestion with strong acids }
$$

where, $\mathrm{n}$ is the concentration of a given element in fraction $\mathrm{n}$.

Single (total) digestion procedure employing strong acids mixture was applied to each sample and replicated four times. The average analytical results acquired are illustrated in Fig. 1. The recovery values of the tested elements for all the four schemes were calculated according to the equation mentioned above and generally, agreed with each other although some recoveries deviated from acceptable values (between 90 and $110 \%$ ) at the $90 \%$ confidence level. It is apparent from Fig. 1 that the recoveries obtained with the Grimalt method were lower for all the metals studied in all the samples, with the exception of Ni in JMS-1. Recovery of $\mathrm{Cr}$ using the Grimalt scheme was poor with values of $75 \%$ for NR; $54 \%$ for TR and $65 \%$ for JMS- 1 . The residual fraction of this scheme for all the elements showed a negative departure consistently. This indicated that for the materials studied the last extraction stage of the Grimalt scheme was unable to remove elements strongly fixed in the crystalline lattice. It must be remarked from Table 2 that no HF was employed and the extraction time was also shorter in that step, preventing an exhaustive attack to the residue. The recovery for $\mathrm{Cr}$ was also comparatively lower with the SM\&T scheme in TR $(87 \%)$ and JMS-1 (83\%) samples, but for NR sample the recovery was $97 \%$, may be due to its muddy nature. Thus, it can be concluded that in this case the other two schemes provided a more complete and reliable fractionation of the metal. On the other hand, the Tessier scheme produced $91-105 \%$ recovery with an exception of $\mathrm{Ni}(84 \%)$ in NR sediment. This may be due to the single extraction, which was done after the method described by Tessier et al. ${ }^{15)}$. Generally, good recoveries were achieved with the Hall procedure and the range was $92-109 \%$ (Fig. 1). However, during the use of sequential extraction schemes for fractionation of metals, sample contamination or loss could occur and this phenomenon may cause the experimental errors, which means, obtaining low or high recovery.
Consequently, because the experimental precision depends not only upon the care taken in performing the multiple extraction steps and the instrumental calibration and measurement, but also on the homogeneity of the treated material, these results are not unexpected ${ }^{22)}$.

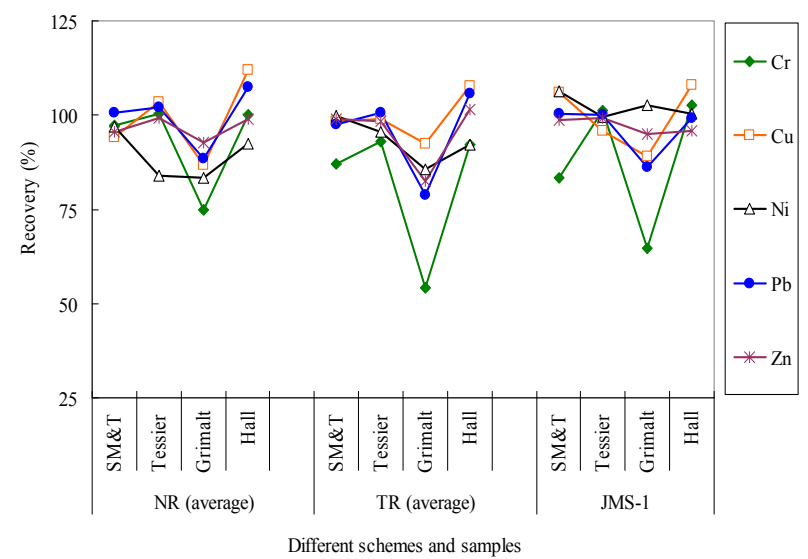

Fig.1 Comparison between the total metal concentrations and sum of fractions among the schemes used on the basis of recovery $(\%)$ in sediments and standard samples.

\section{(3) Influence of sequential extraction schemes on the fractionation pattern of metals at each extraction step}

The comparison among the one 4-step (the SM\&T), the two 5-step (Tessier and Hall) and the one 6-step (Grimalt) sequential extraction procedures was carried with JMS-1 and the four different sediment samples collected from two rivers in Japan. The metal concentrations in percentage based on the summation of all the sequential extraction steps excluding the residual phase fractions, determined at each extraction step for the four different sequential extraction schemes are illustrated in Figs. 2-6. The residual phase was not considered in the comparison because the SM\&T and Grimalt schemes did not employ HF in the dissolution of metal at this phase. Thus, there is some comparability in total phase partitioning of metal, especially for $\mathrm{Cr}$ and $\mathrm{Ni}$. It was also reported earlier that without $\mathrm{HF}$, the extractants are unable to remove metals trapped in the silicate matrices. Thus, preventing an exhaustive attack to the residue ${ }^{25)}$. However, the results obtained from the Figs. 2-6, indicate that each metal has a characteristic distribution pattern. The order of the non-residual fractions (i.e. the first 3-steps for the SM\&T scheme, the first 4-steps for the Tessier and Hall schemes and the first 5-steps for the Grimalt scheme) of the metals in all the samples obtained by the schemes are:

$\mathrm{Zn}>\mathrm{Pb}>\mathrm{Ni}>\mathrm{Cu}>\mathrm{Cr}$ for $\mathrm{SM} \& \mathrm{~T}, \mathrm{~Pb}>\mathrm{Zn}>\mathrm{Cu}>\mathrm{Cr}$ $>\mathrm{Ni}$ for Tessier, $\mathrm{Pb}>\mathrm{Zn}>\mathrm{Cu}>\mathrm{Cr}>\mathrm{Ni}$ for Grimalt and $\mathrm{Pb}>\mathrm{Cu}>\mathrm{Zn}>\mathrm{Ni}>\mathrm{Cr}$ for Hall scheme.

In an average, the lowest mobility was observed 
for $\mathrm{Ni}$ and $\mathrm{Cr}$ for the four extraction schemes. The following sections describe element phase distributions according to the sequential extraction procedures applied in this study. For better comparison and to get much more information on the relative advantages of each schemes, the data obtained from the non-residual phases of the four schemes were grouped into the following three phases: Easily extractable (upto carbonate), Fe-Mn oxides occluded and Organic matter (sulfides) bounded.

\section{a) Chromium}

The majority of $\mathrm{Cr}$ was released from non-residual phases of all the four schemes used for NR (overall range 85-93\%, exception in SM\&T scheme, 65\%) and JMS-1 (overall range 68-69\%, exception in Tessier scheme, 39\%) samples but in case of TR samples, the residual phase was higher (76-87\%) with the exception in the Grimalt $(52 \%)$ and Hall (49\%) schemes. From Fig. 2, it is evident that a relatively high proportion of $\mathrm{Cr}$ in NR samples $(90 \%)$ was bound to organic matter phase of SM\&T scheme and $64-76 \%$ was in Fe-Mn oxides occluded phases of other three schemes. In case of TR and JMS-1 samples, a similar trend was also observed for non-residual $\mathrm{Cr}$. It was apparent from the results for all the samples that the extractants and techniques used in the Fe-Mn oxides occluded and organic matter bounded phases of Hall scheme were more aggressive compared to the extractants used in the others schemes and for this reason the residual phase of this scheme was the lowest among the schemes. On the other hand, the most effective extractants were $0.25 \mathrm{M} \mathrm{NH}_{2} \mathrm{OH} . \mathrm{HCl}$ in $0.25 \mathrm{M} \mathrm{HCl}$ + heating at $60^{\circ} \mathrm{C}$ for $2 \mathrm{hrs}$ and $1 \mathrm{M} \mathrm{NH}_{2} \mathrm{OH} . \mathrm{HCl}$ in $25 \% \mathrm{HOAc}$ + heating at $90^{\circ} \mathrm{C}$ for $3 \mathrm{hrs}$ used for the leaching of $\mathrm{Cr}$ bound to Fe-Mn oxides occluded phase of the Hall scheme (amorphous Fe oxyhydroxide and crystalline Fe oxide, respectively) with an extractable ratio (extracted: total released by single extraction) of $70 \%, 24 \%$ and $43 \%$ for NR, TR and JMS- 1 , respectively. This may be due to the formation of relatively stable organo-metal complexes with more concentrated strong reductant $\left(\mathrm{NH}_{2} \mathrm{OH} . \mathrm{HCl}\right)$ in presence of $\mathrm{HCl}$ and subsequently weak acid (HOAc). Furthermore, heating process may also accelerate the extraction process. This agrees, with some reports ${ }^{26,27)}$ published earlier. However, it is worth mentioning that when the one way ANOVA was done, no significant difference was observed between any two schemes on the basis of the total non residual $\mathrm{Cr}$ contents for all the samples.

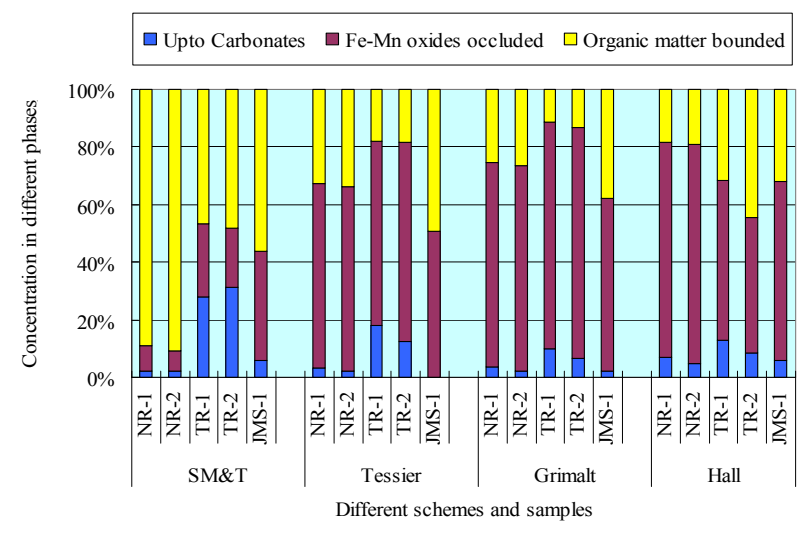

Fig.2 Distribution of $\mathrm{Cr}$ among the different non-residual phases of different schemes in sediments and standard samples.

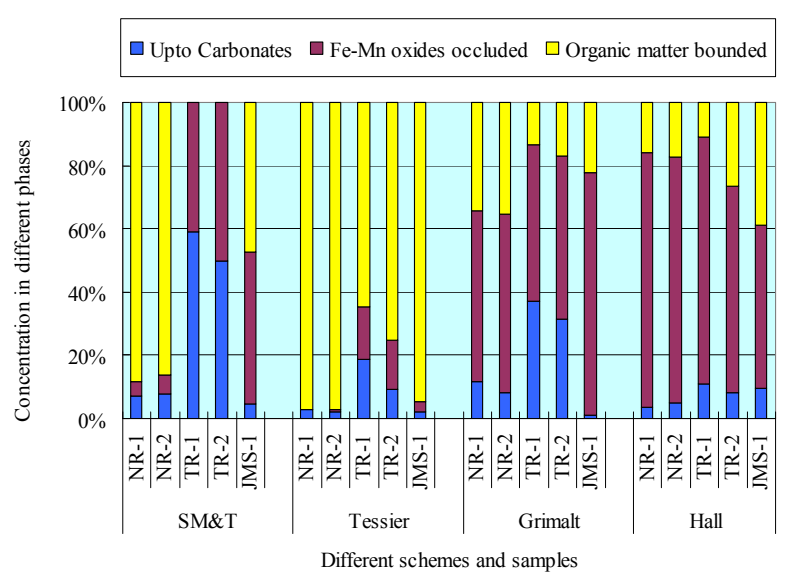

Fig.3 Distribution of $\mathrm{Cu}$ among the different non-residual phases of different schemes in sediments and standard samples.

\section{b) Copper}

The analytical results from each extraction step of all the schemes and samples used for $\mathrm{Cu}$ are illustrated in Fig. 3. The total extractable $\mathrm{Cu}$ content with extractants used in the SM\&T, Tessier and Grimalt schemes were almost similar for NR and JMS-1 (89-91 and 72-79\%, respectively) samples whereas for the Hall scheme, the amount was 97 and $87 \%$, respectively. On the other hand, in case of TR sediments, total non-residual $\mathrm{Cu}$ content with the extractants used among the schemes showed the sequence as: Hall $>$ Grimalt $>$ Tessier $>$ SM\&T. From the Fig. 3, it is evident that the extractants used in the Hall scheme in bound to Fe-Mn oxides occluded phase was more aggressive followed by Grimalt scheme $\left(0.04 \quad \mathrm{M} \quad \mathrm{NH}_{2} \mathrm{OH} . \mathrm{HCl}\right.$ and dissolution in $1 \mathrm{M} \mathrm{HNO}_{3}$ ) and the extractant used in Tessier scheme (0.04 $\mathrm{M} \mathrm{NH}_{2} \mathrm{OH} . \mathrm{HCl}$ in $\left.25 \% \mathrm{HOAc}\right)$ was the least effective, because there was no non-coordinating counter-ion like $\mathrm{HNO}_{3}$ (Table 2). May be this was the reason to obtain the highest amount $(66-96 \%)$ of non-residual $\mathrm{Cu}$ for the extractants used in organic matter bounded phase $\left(0.02 \mathrm{M} \mathrm{HNO}_{3}+30 \% \mathrm{H}_{2} \mathrm{O}_{2}(\mathrm{pH}=2)+\right.$ heating and 
after cooling, shaking 30 min. with $3.2 \mathrm{M} \mathrm{NH}_{4} \mathrm{OAc}$ in $20 \% \mathrm{HNO}_{3}$ ) in Tessier scheme. However, there was no significant difference between any two schemes on the basis of the total non-residual $\mathrm{Cu}$ contents for all the samples by using one way ANOVA.

\section{c) Nickel}

There were significant differences observed between the average non-residual Ni levels of the Hall scheme and the others by using one way ANOVA followed by post hoc test at 99\% level of confidence for all the samples used but among the others three schemes, there were no significant differences found for total non-residual Ni contents. The results for each extraction step are depicted in Fig. 4. It should be noted here that the average residual Ni contents for Hall scheme was lower than the others for all the samples examined. The Fe-Mn oxides occluded phase of Hall scheme (amorphous $\mathrm{Fe}$ oxyhydroxide and crystalline Fe oxide) was the most effective extractants for leaching of $\mathrm{Ni}$ with an extractable ratio (extracted: total released by single extraction) of $40 \%, 53 \%$ and $38 \%$ for NR, TR and JMS-1, respectively and the reason may be the use of more concentrated $\mathrm{NH}_{2} \mathrm{OH} . \mathrm{HCl}$ with $\mathrm{HCl}$ and subsequently HOAc as well as the differences in the extraction conditions (heating) than other schemes. It has been reported by many authors ${ }^{26,27,28)}$ that higher concentration of extractant affected extractability. On the other hand, there are reports that temperature can substantially affect the extractability $^{27}$ and resulted in faster rates of leaching with higher amount of metals ${ }^{26)}$ at $\mathrm{Fe}-\mathrm{Mn}$ oxides occluded phase.

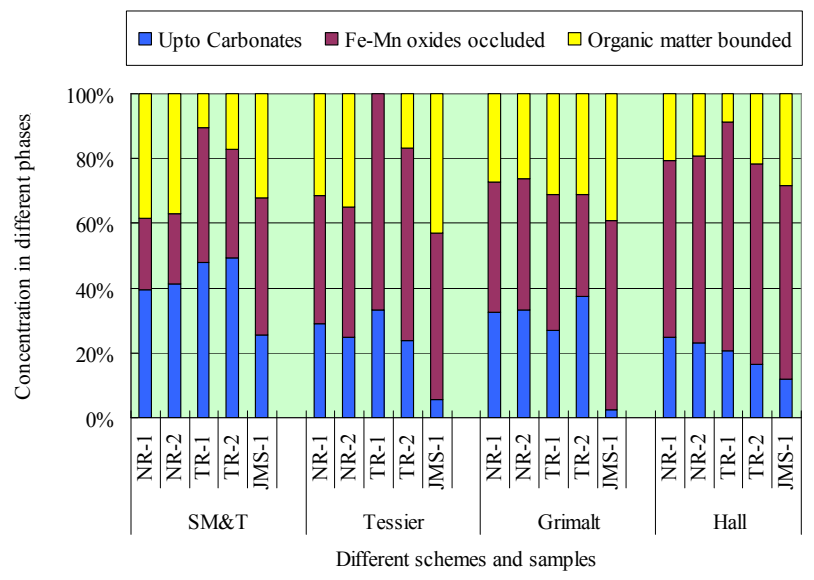

Fig.4 Distribution of Ni among the different non-residual phases of different schemes in sediments and standard samples.

\section{d) Lead}

The analytical results for each extraction step for $\mathrm{Pb}$ are illustrated in Fig. 5. The total extractable $\mathrm{Pb}$ differed between schemes with the overall sequence being: Hall $>$ Grimalt $>$ Tessier $>$ SM\&T. But it should be mentioned here that the sum of total concentration obtained by the different phases of Grimalt scheme was always lower than others for all the samples used (Table 4). It is apparent from Fig. 5 that the Fe-Mn oxides occluded phase of Tessier scheme extracted the lowest amount $(18 \%, 21 \%$ and $66 \%$ for NR, TR and JMS- 1 , respectively) of $\mathrm{Pb}$ among the similar phases of other schemes for all the samples used. However, the subsequent step (organic matter bounded phase) of the Tessier scheme extracted the highest amount (34-80\%) of $\mathrm{Pb}$ compared to the other schemes. This reflects the lower concentration of $\mathrm{NH}_{2} \mathrm{OH} . \mathrm{HCl}(0.04 \mathrm{M})$ and weak acid (HOAc), used in Fe-Mn oxides occluded phase of Tessier scheme. On the other hand, in the same phase of the SM\&T and Grimalt schemes, $\mathrm{HNO}_{3}$ (non-coordinating counter-ion) and in the Hall scheme, $\mathrm{HCl}$ were used with concentrated $\mathrm{NH}_{2} \mathrm{OH} . \mathrm{HCl}$ and replicate extraction was done with more concentrated $\mathrm{NH}_{2} \mathrm{OH} . \mathrm{HCl}$ and $\mathrm{HOAc}$, which may be contributed to extract more $\mathrm{Pb}$ (Table 2). This agrees with the reports ${ }^{26,27,28)}$ published earlier. Finally, the organic matter bounded phase $(750 \mathrm{mg}$ $\mathrm{KClO}_{3}+12 \mathrm{M} \mathrm{HCl}+\mathrm{H}_{2} \mathrm{O}+4 \mathrm{M} \mathrm{HNO}_{3}$ + heating at $90^{\circ} \mathrm{C}$ for $20 \mathrm{~min}$.) of Hall scheme showed the poorest effect for leaching this metal may be due to the effectiveness of the previous phases. On the other hand, it is well known that $\mathrm{Pb}$ forms stable complexes with acetate ${ }^{1,29)}$, which was used in other three schemes with $\mathrm{H}_{2} \mathrm{O}_{2}$. However, the total non-residual $\mathrm{Pb}$ contents for the SM\&T scheme differ significantly from the others schemes at $95 \%$ level of confidence for all the samples used by using one way ANOVA followed by post hoc test but among the other three schemes, there were no significant differences for total non-residual $\mathrm{Pb}$ content.

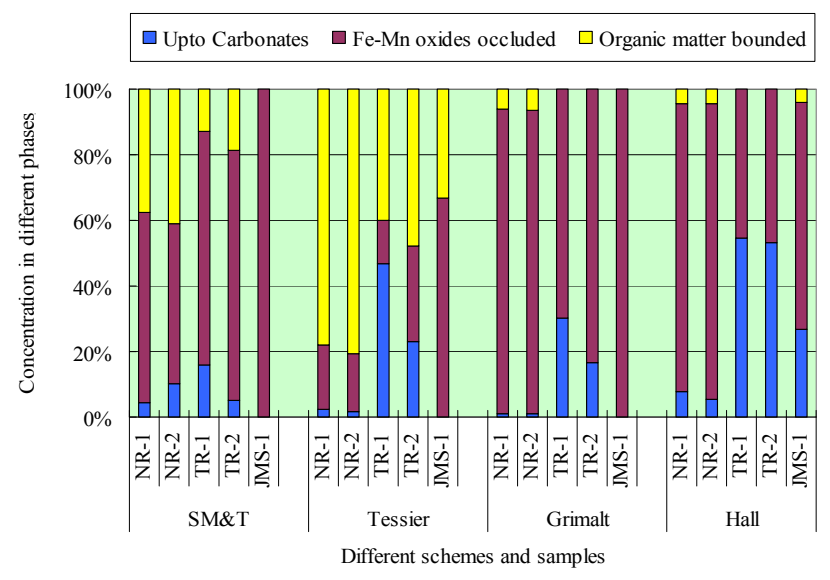

Fig.5 Distribution of $\mathrm{Pb}$ among the different non-residual phases of different schemes in sediments and standard samples. 
e) Zinc

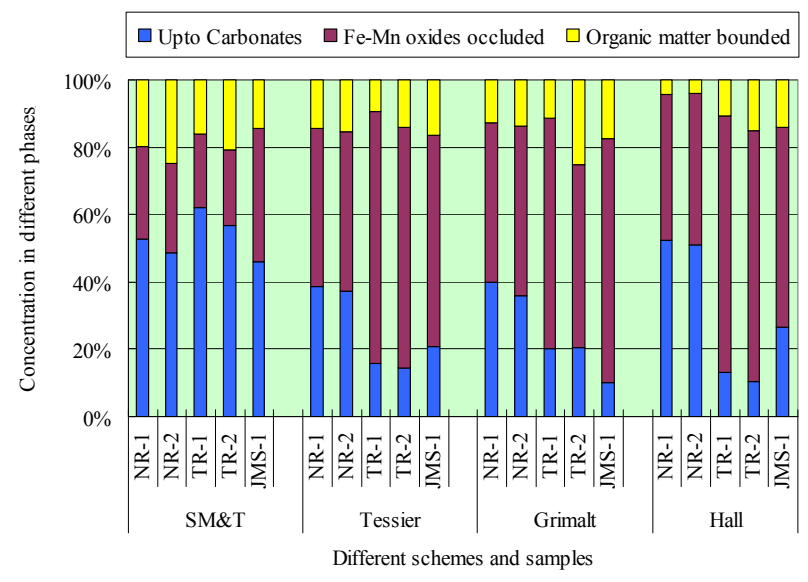

Fig.6 Distribution of $\mathrm{Zn}$ among the different non-residual phases of different schemes in sediments and standard samples.

The total non-residual $\mathrm{Zn}$ contents were approximately 52-92\%, 58-92\%, 72-94\% and $84-96 \%$ for the schemes SM\&T, Tessier, Grimalt and Hall, respectively. The results for each extraction step of the four extraction procedures are depicted in Fig. 6. As a consequence, there were no significant differences between the total non-residual $\mathrm{Zn}$ contents for all the samples and all sequential schemes at $95 \%$ confidence level. However, it is evident from Fig. 6 that the easily extractable phase of the SM\&T scheme (extractant: $0.11 \mathrm{M}$ acetic acid $+16 \mathrm{hrs}$ stirring) had slightly more leaching capacity than the others three schemes (extractants for all: $1 \mathrm{M}$ sodium acetate of $\mathrm{pH} 5+$ 6hrs stirring) for all the samples. It should also be mentioned here, in Hall scheme the amount of extractant was more than twice than Tessier and Grimalt schemes [Table 2], which may contribute to release more $\mathrm{Zn}$ in this phase. So this was obviously, due to the nature and amount of extractants as well as extraction condition used in the scheme. Furthermore, Fig. 6 also reflects that the Fe-Mn oxides occluded phase of the three schemes (except SM\&T) had more effectiveness for the fractionation of $\mathrm{Zn}$. The sequence of the schemes on the basis of the most effective extractant in this phase for all the samples was: Hall $>$ Tessier $\geqq$ Grimalt. Shiowatana et $\mathrm{al}^{26}{ }^{26}$ reported that ambient temperature is unable to completely extract the reducible phase. They also found further leaching occurring when temperature raised from $65^{\circ} \mathrm{C}$ to $80^{\circ} \mathrm{C}$ especially for $\mathrm{Zn}$ and Fe. Differences in the extraction conditions among the schemes, and in particular, the ability of the chemical reagents used in each case to target particular geochemical phases, should affect all metals more or less in the same way. Furthermore, during sequential extraction procedures each metal would behave according to its physicochemical properties. According to Mester et al. ${ }^{1}$, among the metals studied, $\mathrm{Zn}$ has the most stability over a wide Eh-pH range in solution and it could be easily extracted without any redistribution effects.

\section{CONCLUSIONS}

The results of heavy metal fractionation in sediment samples obtained by four commonly used sequential extraction schemes were compared in terms of the distribution and bioavailability of metals at each extraction step. The highest mobility was observed for $\mathrm{Pb}$ and $\mathrm{Zn}$ among the four schemes while the lowest was for $\mathrm{Cr}$ and $\mathrm{Ni}$. A significant fraction of the four metals (except $\mathrm{Ni}$ ) appear as bound to Fe-Mn oxides especially for NR sediments, in agreement with the occurrence of minerals of the iron oxide group observed by the XRD analysis. This is well known that the sequential extraction procedures and the reagents used have substantially different effectiveness for extracting and/ or partitioning of the metals from the sediment samples, that is, the extractable heavy metal contents can be altered depending on the operational conditions used. In addition, there are a number of factors affecting a sequential extraction procedure such as, readsorption, concentration and type of the reagent, aim of application and others. However, with little exception, similarities in the distribution patterns resulting from all the sequential extraction schemes were observed.

Finally, on the basis of the obtained results of this study, the Hall method may be recommended as its extractability, reproducibility as well as stability of the results was comparatively higher than others. For all the studied elements, the Fe-Mn oxides occluded phase of this scheme was the most effective owing to the high tendency to form stable complexes for both the target phases and the analyte elements.

ACKNOWLEDGMENT: This work is partially supported by the 21st century COE program, Life Conjugated Chemistry (LCC), Keio University, Japan. The first author also gratefully acknowledges the financial support as Fellowship provided by the Yoshida Scholarship Foundation, 3-22-1 Kamezawa, Sumida-ku, Tokyo, Japan.

\section{REFERENCES}

1) Mester, Z., Cremisini, C., Ghiara, E. and Morabito, R. : Comparison of two sequential extraction procedures for 
metal fractionation in sediment samples. Analytica Chimica Acta, Vol. 359, pp. 133- 142, 1998.

2) Marin, A., Lopez-Gonzalvez, A. and Barbas, C. : Development and validation of extraction methods for determination of zinc and arsenic speciation in soils using focused ultrasound: Application to heavy metal study in mud and soils. Analytica Chimca Acta, Vol. 442, pp. 305-318, 2001.

3) López-Sánchez, J. F., Rubio, R., Samitier, C. and Rauret, G. : Trace metal partitioning in marine sediments and sludges deposited off the coast of Barcelona (Spain). Water Research, Vol. 30 No. 1, pp. 153- 159, 1996.

4) Weisz, M., Polyak, K. and Hlavay, J. : Fractionation of elements in sediment samples collected in rivers and harbors at Lake Balaton and its catchment area. Microchemical Journal, Vol. 67 Nos. 1-3, pp. 207- 217, 2000.

5) Kuang-Chung Y., Li-Jyur T., Shih-Hsiung C. and Shien-Tsong H. : Correlation analyses on binding behavior of heavy metals with sediment matrices. Water Research, Vol. 35, No. 10, pp. 2417- 2428, 2001.

6) Sutherland, R. A. and Tack, F. M. G. : Determination of Al, $\mathrm{Cu}, \mathrm{Fe}, \mathrm{Mn}, \mathrm{Pb}$ and $\mathrm{Zn}$ in certified reference materials using the optimized BCR sequential extraction procedure. Analytica Chimica Acta, Vol. 454, pp. 249- 257, 2002.

7) Morillo, J., Usero, J. and Gracia, I. : Heavy metal fractionation in sediments from the Tinto River (Spain). International Journal of Environmental Analytical Chemistry, Vol. 82, No. 4, pp. 245- 257, 2002.

8) O'Neill, P., Williams, J., Bancroft, K. C. C., Davis, R. D. and Campbell, J. A. : International Conference on Heavy Metals in the Environment, Athens, Greece, Vol. 1, p. 582, 1985.

9) Gunn, A. M., Winnard, D. A. and Hunt, D. T. E. : Trace metal speciation in sediments and soils. In: Metal Speciation: Theory, Analysis and Application, Kramer, R. J. and Allen, H. E. (Eds.), Chelsia: Lewis Pub. Inc., pp. 261- 294, 1988.

10) Kersten, M. and Forstner, U. : Speciation of trace elements in sediments. In: Trace Element Speciation: Analytical Methods and Problems, Batley G. E. (Ed.), Boca-Raton: CRC Press, pp. 245- 318, 1989.

11) López-Sánchez, J. F., Rubio, R. C. and Rauret, G. : Comparison of two sequential extraction procedures for trace metal partitioning in sediments. International Journal of Environmental Analytical Chemistry, Vol. 51, pp. 113121, 1992.

12) Filgueiras, A. V., Lavilla, I. and Bendicho, C. : Chemical sequential extraction for metal partitioning in environmental solid samples. Journal of Environmental Monitoring, Vol. 4, No. 6, pp. 823-857, 2002.

13) Parat, C., Leveque, J., Dousset, S., Chaussod, R. and Andreaux, F. : Comparison of three sequential extraction procedures used to study trace metal distribution in an acidic sandy soil. Analytical and Bioanalytical Chemistry, Vol. 376, pp. 243- 247, 2003.

14) Rauret, G., Lopez-Sanchez, J. F., Sahuquillo, A., Rubio, R., Davidson, C., Ure, A. and Quevauviller, Ph. : Improvement of the BCR three step sequential extraction procedure prior to the certification of new sediment and soil reference materials. Journal of Environmental Monitoring, Vol. 1, pp. 57- 61, 1999.
15) Tessier, A., Campbell, P. G. C. and Bisson, M. : Sequential extraction procedure for the speciation of particulate trace metals. Analytical Chemistry, Vol. 51, No. 7, pp. 844- 851, 1979.

16) Grimalt, J.O. : Sampling, sample handling and operational methods for the analysis of trace pollutants in the marine environment. In: Marine Pollution, Albaiges J. (Ed.), New York: Hemisphere Publishing Corp., pp. 223- 278, 1989.

17) Hall, G. E. M., Gauthier, G., Pelchat, J-C., Pelchat, P. and Vaive, J. E. : Application of a sequential extraction scheme to ten geological certified reference materials for the determination of 20 elements. Journal of Analytical Atomic Spectrometry, Vol.11, No. 9, pp. 787- 796, 1996.

18) Terashima, S., Imai, N., Taniguchi, M., Okai, T. and Nishimura, A. : The preparation and preliminary characterisation of four new Geological Survey of Japan geochemical reference materials: Soils, JSO-1 and JSO-2; and marine sediments, JMS-1 and JMS-2. Geostandards Newsletter, Vol. 26, No. 1, pp. 85- 94, 2002.

19) Tsuno, H., Ohta, A., Kagi, H., Imai, N., Tao, H. and Nomura, M. : Speciation of chromium in artificially contaminated soil reference material GSJ, JSO-2 using XANES and chemical extraction methods. Geostandard and Geoanalytical Research, Vol. 30, No. 1, pp. 55- 62, 2006.

20) Douglas, C. M. : Design and Analysis of Experiments, $\left(5^{\text {th }}\right.$ ed.) New York: John Wiley \& Sons., Inc., p. 96, 2001.

21) Davidson, C. M., Thomas, R. P., McVey, S. E., Perala, R., Littlejohn, D. and Ure, A. M. : Evaluation of a sequential extraction procedure for the speciation of heavy metals in sediments. Analytica Chimica Acta, Vol. 291, No. 3, pp. 277- 286, 1994.

22) Hall, G. E. M., Vaive, J. E., Beer, R. and Hoashi, M. : Selective leaches revisited, with emphasis on the amorphous Fe oxyhydroxide phase extraction. Journal of Geochemical Exploration, Vol. 56, pp. 59- 78, 1996.

23) Quevauviller, Ph. : Operationally defined extraction procedures for soil and sediment analysis: I. Standardization II. Certified reference materials. Trends in Analytical Chemistry, Vol. 17, Nos. 5 \& 10, pp. 289- 298 \& 632- 642, 1998.

24) Sutherland, R. A., Tack, F. M. G., Tolosa, C. A. and Verloo, M. G. : Operationally defined metal fractions in road deposited sediment, Honolulu, Hawaii. Journal of Environmental Quality, Vol. 29, pp. 1431- 1439, 2000.

25) Alvarez, M. B., Malla, M. E. and Batistoni, D. A. : Comparative assessment of two sequential chemical extraction schemes for the fractionation of cadmium, chromium, lead and zinc in surface coastal sediments. Fresenius Journal of Analytical Chemistry, Vol. 369, pp. 8190, 2001.

26) Shiowatana, J., Tantidanai, N., Nookabkaew, S. and Nacapricha, D. : Heavy metals in the environment: a novel continuous-flow sequential extraction procedure for metal speciation in solids. Journal of Environmental Quality, Vol. 30, pp. 1195- 1205, 2001.

27) Sahuquillo, A., Lopez-Sanchez, J. F., Rubio, R., Rauret, G., Thomas, R. P., Davidson, C. M. and Ure, A. M. : Use of a certified reference material for extractable trace metals to assess sources of uncertainty in the BCR three stage 
Zakir, H. M. et al.

sequential extraction procedure. Analytica Chimica Acta, Vol. 382, pp. 317- 327, 1999.

28) Maiz, I., Esnaola, M. V. and Millan, E. : Evaluation of heavy metals availability in contaminated soils by a short sequential extraction procedure. Science of the Total Environment, Vol. 206, pp. 107- 115, 1997.
29) Skoog, D. A., West, D. M. and Holler, F. J. : Fundamentals of Analytical Chemistry, Orlando: Saunders College Publishing, p. 48, 1992.

(Received November 2, 2007) 